\title{
Possible Association between Serotonin Transporter Gene Polymorphism and Violent Suicidal Behavior in Mood Disorders
}

\author{
Frank Bellivier, Andreï Szöke, Chantal Henry, Jérome Lacoste, Corinne Bottos, \\ Marika Nosten-Bertrand, Patrick Hardy, Frederic Rouillon, Jean-Marie Launay, \\ Jean-Louis Laplanche, and Marion Leboyer
}

Background: Genes involved in the serotonin system are major candidates in association studies of suicidal behavior. In this case-control study we investigated whether the serotonin transporter (5-HTT) gene encoding the protein responsible for the reuptake of serotonin from the synapse after its release from serotonergic neurons is a susceptibility factor for suicidal behavior.

Methods: A functional polymorphism of the 5-HTT gene (a 44-base pair insertion/deletion in the 5-HTT-linked polymorphic region [5-HTTLPR]) was studied in a population of 237 consecutive patients with affective disorder (unipolar or bipolar) and 187 control subjects. Ninetynine patients had attempted suicide at least once, of whom 26 made a violent attempt.

Results: No association was found between the "s" allele of the 5-HTTLPR and suicide attempt; however, there was a significant difference in allele distributions between patients who had made violent suicide attempts and control subjects.

Conclusions: A genetic variant of the 5-HTT gene may predispose individuals to violent suicidal behavior. The precise phenotype associated with the 5-HTT gene is unclear, and therefore further studies are required to replicate these findings. Biol Psychiatry 2000;48: 319-322 (c) 2000 Society of Biological Psychiatry

Key Words: Serotonin transporter gene, affective disorder, suicidal behavior, candidate symptoms

From the Service de Psychiatrie Adulte (Pr Rouillon), Hôpital Henri Mondor et Albert Chenevier, Assistance Publique-Hôpitaux de Paris, Créteil (FB, AS, FR, ML), Service de Psychiatrie Adulte ( $\operatorname{Pr}$ M. Bourgeois), Hôpital Charles Perrens, Bordeaux (CH, JL), Laboratoire Central de Biochimie et de Biologie Moléculaire, Hôpital Lariboisière, Assistance Publique-Hôpitaux de Paris, Paris (CB, J-ML, J-LL), Unité Neurobiologie et psychiatrie (INSERM U513), Faculté de médecine de Créteil, Créteil (FB, MN-B, FR, ML), and Service de Psychiatrie Adulte ( $\operatorname{Pr}$ Feline), Hôpital de Bicêtre, Assistance PubliqueHôpitaux de Paris, Le Kremlin Bicêtre (PH), France.

Address reprint requests to Frank Bellivier, Hôpital Henri Mondor, Service de psychiatrie Adulte, 51, avenue du Mal de Lattre de Tassigny, 94010 CRETEIL cedex, France.

Received July 1, 1999; revised October 11, 1999; revised March 17, 2000; accepted March 22, 2000.

\section{Introduction}

The involvement of genetic vulnerability factors in suicidal behavior is supported by familial, twin, and adoption studies (Roy et al 1997a). Several studies have suggested that the genetic vulnerability factors underlying suicidal behavior are independent of and in addition to the genetic transmission of psychiatric disorders comorbid with suicidal behavior (i.e., manic-depressive disorder, schizophrenia, alcoholism...; Brent et al 1996; Mann 1998; Roy et al 1997b).

Altered serotonergic function in suicide is one of the most replicated findings in modern biological psychiatry (for review, see Mann 1998). Studies of various serotonin indicators have shown that low levels of serotonergic neurotransmission are associated with suicidal behavior rather than with the primary psychiatric diagnosis (Mann 1998). These findings have been consistently replicated in the subgroup of patients who have used violent methods (Mann 1998). Thus, genetic factors may affect violent suicide risk by reducing serotonergic neurotransmission (Mann 1998). The serotonin transporter (5-HTT) gene is a major candidate gene for suicidal behavior (Mann 1998). The serotonin transporter is responsible for the sodiumdependent reuptake of serotonin from the synapse after its release from serotonergic neurons (Rudnick and Clark 1993). Thus, 5-HTT plays a key role in regulating synapse levels of available serotonin and serotonin turnover.

A functional polymorphism of the 5-HTT gene has been described: a 44-base pair (bp) insertion/deletion in the 5-HTT gene-linked polymorphic region (5-HTTLPR; two alleles: "long" [1] and "short" [s]; Heils et al 1996). We investigated the possible involvement of the 5-HTT gene in suicidal behavior, by studying the 5-HTTLPR polymorphism of the 5-HTT gene in a sample of patients with affective disorders with and without a history of suicide attempts and in control subjects. The subgroup of patients with violent suicide attempts were also tested for association with the 5-HTTLPR. 


\section{Methods and Materials}

\section{Populations}

Consecutive patients, meeting the DSM-IV criteria for unipolar (UP; recurrent major depressive episode) or bipolar (BP) disorder, were recruited. Patients and healthy volunteers were included in the study after giving informed consent. Patients were recruited at the psychiatric units of the Assistance PubliqueHôpitaux de Paris and at the Charles Perrens Hospital in Bordeaux. The control subjects were blood donors at the PitiéSalpétrière Hospital (Paris).

Patients and control subjects were all white and of French descent (at least three grandparents from mainland France). They were interviewed by trained psychiatrists, using a French version of the Diagnostic Interview for Genetic Studies (Nurnberger et al 1994). To reduce morbidity among subjects in the control group, only individuals older than 35 years were included. Control subjects with a personal or family history of mood disorders or suicide attempts were excluded. A suicide attempt was defined as an attempt by the subject to kill him- or herself, resulting in the need for medical treatment at a hospital. The seriousness and severity of the medical consequences of the attempt were rated using the six-point scale of the Diagnostic Interview of Genetic Studies. Suicide attempts were classified as violent or nonviolent according to the criteria proposed by Asberg et al (1976). Hanging attempts, the use of firearms or knives, and jumping from heights were classed as violent attempts; drug overdoses were considered to be nonviolent suicide attempts.

\section{Genetic Analysis}

DNA was prepared from peripheral blood leukocytes by standard procedures. The insertion/deletion in the 5-HTTLPR was amplified with primers 5'-GGCGTTGCCGCTCTGAATC-3' (forward, strp5) and 5'-GAGGGACTGAGCTGGACAACCAC-3' (reverse strp3); (Collier et al 1996). Polymerase chain reaction was performed using standard protocols except that deoxyguanosine triphosphate (dGTP) was replaced by 7-deazadGTP. Annealing temperatures were as follows: $63^{\circ} \mathrm{C}$ for two cycles, $62^{\circ} \mathrm{C}$ for two cycles, and $61^{\circ} \mathrm{C}$ for 34 cycles. Allele sizes were determined by the comparison of bands with size standards after electrophoresis in an $8 \%$ polyacrylamide gel and silver staining. Amplification gave two alleles differing by $44 \mathrm{bp}$ (1 and s).

\section{Statistical Analysis}

Allele and genotype distributions in patients and control subjects were compared using the $\chi^{2}$ test. Odds ratios with 95\% confidence intervals were calculated by Woolf's method. For contingency tables with a small number of subjects (less than five), the exact probability was calculated using the CLUMP program (10,000 simulations; Sham and Curtis 1995). The Armitage linearity tendency test was used a test for a dose effect for susceptibility alleles (Armitage and Berry 1987, 371-407). A significance level of .05 was used.

\section{Results}

The total sample consisted of 194 BP patients (116 women and 78 men), 43 UP patients ( 32 women and 11 men), and 187 control subjects (77 women and 110 men). Ninetynine patients had attempted suicide at least once (18 UP and $81 \mathrm{BP}$ ), of whom 73 had made a nonviolent and 26 a violent suicide attempt. One hundred eighty-four control subjects and 233 patients were typed for the 5-HTTLPR polymorphism.

The 5-HTTLPR genotype frequencies were in HardyWeinberg equilibrium in control subjects and BP and UP patients.

For the 5-HTTLPR, the s allele frequency was .41 in control subjects, .44 in patients without suicidal behavior, and .49 in patients who had attempted suicide. No association was found between the s allele of the 5-HTTLPR and suicidal behavior $\left[\chi^{2}(1)=3.68, p=.055\right.$; Table 1]. Among patients with a history of suicide attempts, the $s$ allele frequency was highest in patients who had attempted suicide by violent means (.58). For allele distributions, there was a significant difference between patients with violent suicide attempts and control subjects $\left[\chi^{2}(1)=5.2\right.$, $p=.023]$. The odds ratio for violent suicide attempts associated with the s allele was 2 (95\% confidence interval $=1.1-3.6)$. The more severe the phenotype (control subjects, no suicidal behavior, nonviolent suicide attempt, and violent suicide attempt, in ascending order of violence), the higher was the frequency of the $\mathrm{s}$ allele [Table 1, Armitage linearity tendency test: $\chi^{2}(1)=4.73$, $p=.029]$.

\section{Discussion}

The s allele frequency (5-HTTLPR) of our control population $(41 \%)$ was consistent with those reported in white control subjects by Collier (42\%; Collier et al 1996), Furlong (41.1\%; Furlong et al 1998), and Hoehe (41.6\%; Hoehe et al 1998).

The 5-HTTLPR polymorphism of the 5-HTT gene was associated with violent suicidal behavior in patients with affective disorders, whereas patients without suicidal behavior were similar to control subjects. Several positive and negative associations between UP and BP affective disorder and the 5-HTTLPR have been reported (for review, see Bellivier et al 1998). Other phenotypes have also been found to be associated with the 5-HTTLPR. These include seasonal affective disorder (Rosenthal et al 1998) and anxiety-related trait (Lesch et al 1996). If confirmed, our data would account for the conflicting results obtained in association studies involving the 5-HTTLPR. Indeed, the groups of patients included in previous studies probably contained various proportions of the 
Table 1. Genotype Distributions for the 5-HTTLPR Polymorphism in Patients with Affective Disorder $(N=233)$ and Control Subjects $(N=184)$

\begin{tabular}{|c|c|c|c|c|c|}
\hline & 11 & 1s & ss & 1 & $\mathrm{~s}$ \\
\hline \multicolumn{6}{|l|}{ Genotype distribution } \\
\hline Patients with at least one suicide attempt & $25(25.7)$ & $48(49.5)$ & $24(24.7)$ & $98(50.5)$ & $96(49.5)^{c}$ \\
\hline Patients with violent suicide attempt & $2(8)$ & $17(68)$ & $6(24)$ & $21(42)$ & $29(58)^{b}$ \\
\hline Patients with nonviolent suicide attempt & $23(31.9)$ & $31(43.1)$ & $18(25)$ & $77(54)$ & $67(46)^{c}$ \\
\hline Patients with no suicide attempt & $43(31.6)$ & $67(49.3)$ & $26(19.1)$ & $153(56)$ & $119(44)^{d}$ \\
\hline Controls & $60(32.6)$ & $97(52.7)$ & $27(14.7)$ & $217(59)$ & $151(41)^{e}$ \\
\hline \multicolumn{6}{|l|}{ Allele distribution } \\
\hline \multicolumn{6}{|l|}{ Patients with at least one suicide attempt ${ }^{a}$} \\
\hline \multicolumn{6}{|l|}{ Patients with violent suicide attempt ${ }^{b}$} \\
\hline \multicolumn{6}{|l|}{ Patients with nonviolent suicide attempt ${ }^{c}$} \\
\hline \multicolumn{6}{|l|}{ Patients with no suicide attempt ${ }^{d}$} \\
\hline Controls $^{e}$ & & & & & \\
\hline
\end{tabular}

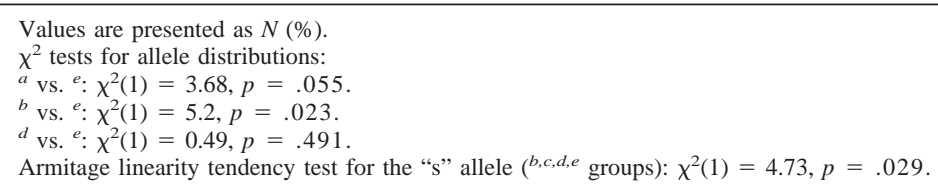

subgroup associated with the 5-HTTLPR (i.e., patients with violent suicidal behavior). Our results are consistent with the study of P. Gorwood and colleagues (personal communication, 1999), who reported an association between the 5-HTTLPR s allele and violent suicidal behavior in alcoholic patients, suggesting the existence of a vulnerability factor for suicidal behavior independent of the primary psychiatric diagnosis. This is also consistent with the biological abnormalities in violent suicide cases, being independent of the psychiatric diagnosis. In our sample there was an association between alcohol dependence and suicide attempt in patients with affective disorder $\left[\chi^{2}(1)=\right.$ $5.34, p=.028]$; however, there was no association between alcohol dependence and the 5-HTTLPR (difference in genotype distribution between patients with alcohol dependence and control subjects, exact $p=.23$ ).

Suggestions have been made as to how the 5-HTTLPR may act as a risk factor for suicidal behavior. The 5-HTTLPR polymorphism is located in the regulatory region of the 5-HTT gene and the short form of the promoter is associated with lower levels of expression of the gene (Lesch et al 1996). Homozygosity for the s allele results in low levels of transmembrane transport of 5-HT in lymphoblastoid cell lines (Heils et al 1996). This is consistent with previous reports showing low 5-HT levels in the brains of individuals who have committed suicide (Heils et al 1996) and low levels of 5-HT uptake in these patients. It is also consistent with studies showing reduced binding of $\left[{ }^{3} \mathrm{H}\right]$ imipramine and $\left[{ }^{3} \mathrm{H}\right]$ paroxetine to brain 5-HT uptake sites and transporters in individuals who have committed suicide (Owens and Nemeroff 1994).

Our study has several limitations. We used strict geographic inclusion criteria for patients and control subjects, but our results may still be false positive due to stratifica- tion bias. In addition, the sample of BP patients with suicidal behavior has already been tested for few candidate gene markers, and in the present study several subgroups of patients were tested for association. This results in a higher risk of false positive findings due to multiple testing.

Our sample of UP and BP patients was not selected based on the presence of a history of suicide attempts, so our findings can be considered to be exploratory. Therefore, although our findings are consistent with the association reported by P. Gorwood and colleagues (personal communication, 1999), they should be interpreted with caution. The implication of a 5-HTT gene variant in susceptibility to violent suicidal behavior requires replication using other samples of patients with suicidal behavior, regardless of their psychiatric diagnosis.

This research was supported by grants from Assistance Publique (Contrat de Recherche Clinique 940232) and Institut National de la Santé et de la Recherche Médicale (F. Bellivier, poste d'accueil INSERM). We thank the Blood Transfusion Centre at the Pitié-Salpétrière Hospital (Dr. Jean-Louis Beaumont and Dr. Anne Mercadier) for technical assistance. We also thank the Banque de cellule at the Cochin-Port Royal Hospital (Dr. D. Recan and Pr. M. Delpech).

\section{References}

Armitage P, Berry G (1987): Statistical Methods in Medical Research. Oxford, UK: Blackwell Scientific.

Asberg M, Traskman L, Thoren P (1976): 5-HIAA in the cerebrospinal fluid. A biochemical suicide predictor? Arch Gen Psychiatry 33:1193-1197.

Bellivier F, Henry C, Szoke A, Schurhoff F, Nosten-Bertrand M, Feingold J, et al (1998): Serotonin transporter gene polymor- 
phisms in patients with unipolar or bipolar depression. $\mathrm{Neu}$ rosci Lett 255:143-146.

Brent DA, Bridge J, Johnson BA, Connolly J (1996): Suicidal behavior runs in families. A controlled family study of adolescent suicide victims. Arch Gen Psychiatry 53:11451152.

Collier DA, Stober G, Li T, Heils A, Catalano M, Di Bella D, et al (1996): A novel functional polymorphism within the promoter of the serotonin transporter gene: Possible role in susceptibility to affective disorders. Mol Psychiatry 1:453460.

Furlong RA, Ho L, Walsh C, Rubinsztein JS, Jain S, Paykel ES, et al (1998): Analysis and meta-analysis of two serotonin transporter gene polymorphisms in bipolar and unipolar affective disorders. Am J Med Genet 81:58-63.

Heils A, Teufel A, Petri S, Stober G, Riederer P, Bengel D, Lesch KP (1996): Allelic variation of human serotonin transporter gene expression. J Neurochem 66:2621-2624.

Hoehe MR, Wendel B, Grunewald I, Chiaroni P, Levy N, Morris-Rosendahl D, et al (1998): Serotonin transporter (5-HTT) gene polymorphisms are not associated with susceptibility to mood disorders. Am J Med Genet 81:1-3.

Lesch KP, Bengel D, Heils A, Sabol SZ, Greenberg BD, Petri S, et al (1996): Association of anxiety-related traits with a polymorphism in the serotonin transporter gene regulatory region. Science 274:1527-1531.
Mann JJ (1998): The neurobiology of suicide. Nat Med 4:25-30.

Nurnberger JJ, Blehar M, Kauffmann C, York-Cooler C, Simpson SG, Harkavy-Friedman J, et al (1994): Diagnostic interview for genetic studies. Rationale, unique features, and training. NIMH Genetics Initiative. Arch Gen Psychiatry 51:849-859.

Owens MJ, Nemeroff CB (1994): Role of serotonin in the pathophysiology of depression: Focus on the serotonin transporter. Clin Chem 40:288-295.

Rosenthal NE, Mazzanti CM, Barnett RL, Hardin TA, Turner EH, Lam GK, et al (1998): Role of serotonin transporter promoter repeat length polymorphism (5-HTTLPR) in seasonality and seasonal affective disorder. Mol Psychiatry 3:175-177.

Roy A, Rylander G, Sarchiapone M (1997a): Genetic studies of suicidal behavior. Psychiatry Clin North Am 20:595-611.

Roy A, Rylander G, Sarchiapone M (1997b): Genetics of suicides. Family studies and molecular genetics. Ann $N Y$ Acad Sci 836:135-157.

Rudnick G, Clark J (1993): From synapse to vesicle: The reuptake and storage of biogenic amine neurotransmitters. Biochem Biophys Acta 1144:249-263.

Sham PC, Curtis D (1995): Monte Carlo tests for associations between disease and alleles at highly polymorphic loci. Ann Hum Genet 59:97-105. 